\title{
Urinary albumin excretion rate and 24-h ambulatory blood pressure in NIDDM with microalbuminuria: effects of a monounsaturated-enriched diet
}

\author{
S. Nielsen, K.Hermansen, O. W. Rasmussen, C. Thomsen, C. E. Mogensen \\ Medical Department M (Endocrinology and Diabetes), Aarhus Kommunehospital and Medical Department C (Diabetes and \\ Endocrinology), Aarhus, Denmark
}

Summary Previous studies have shown that unsaturated fat-enriched diets may have a beneficial effect on blood pressure in non-insulin-dependent diabetic (NIDDM) patients, whereas little is known about the effects on albuminuria. In a 3-week cross-over design we compared the effects of a currently recommended high-carbohydrate diet $(50 \%$ carbohydrate, $30 \%$ fat $[10 \%$ monounsaturated fat]) vs a diet rich in monounsaturated fat $(30 \%$ carbohydrate, $50 \%$ fat $[30 \%$ monounsaturated fat]) on urinary albumin excretion rate, 24-h ambulatory blood pressure and metabolic control in ten NIDDM patients with persistent microalbuminuria. The 24-h ambulatory blood pressure was similar before and after both the high-carbohydrate diet (mean \pm SD: 145/78 $\pm 25 / 10$ vs $143 / 79 \pm 19 / 10 \mathrm{mmHg}$ (NS) and the monounsaturated fat diet: $140 / 78 \pm 16 / 8$ vs $143 / 79 \pm 15 / 8 \mathrm{mmHg}$ (NS). No changes were observed in day or nighttime blood pressures. Urinary albumin excretion rate was unaffected after 3 weeks' treatment by the diets: from (geometric mean $\times / \div$ tolerance factor) $32.4 \times / \div 2.1$ to $36.0 \times / \div 1.9 \mu \mathrm{g} / \mathrm{min}$ (NS) vs from
$34.2 \times 1 \div 1.9$ to $32.1 \times 1 \div 2.1 \mu \mathrm{g} / \mathrm{min}$ (NS). Fasting plasma glucose, serum fructosamine and $\mathrm{HbA}_{1 \mathrm{c}}$ as well as lipid and lipoprotein concentrations were stable during both diets. Compared to the high-carbohydrate diet a reduction in the LDL/HDL cholesterol ratio was observed during the monounsaturated fat diet $(p<0.03)$. In conclusion, compared to a high-carbohydrate diet, 3 weeks' treatment with a monounsaturated fat diet did not affect the levels of 24-h ambulatory blood pressure or albuminuria in microalbuminuric NIDDM patients. Moreover, glycaemic control and lipoprotein levels were unchanged, although a potential beneficial effect on the LDL/HDL-cholesterol ratio was noted. Monounsaturated fat represents an alternative in the diets of NIDDM patients especially when caloric intake is not a concern. [Diabetologia (1995) 38: 1069-1075]

Key words Non-insulin-dependent diabetes mellitus; microalbuminuria, blood pressure, monounsaturated fat diet, olive oil, diet, metabolic control.
In non-insulin-dependent diabetes mellitus (NIDDM) a slight elevation in urinary albumin excretion rate (UAE), so-called microalbuminuria (de-

Received: 4 January 1995 and in revised form: 13 March 1995

Corresponding author: Dr. S. Nielsen, Medical Department M (Endocrinology and Diabetes), Aarhus Kommunehospital, DK-8000 Aarhus, Denmark

Abbreviations: UAE, Urinary albumin excretion rate; NIDDM, non-insulin-dependent diabetes mellitus; MUFA, monounsaturated fatty acids; PUFA, polyunsaturated fatty acids; ANOVA, analysis of variance; $\mathrm{CHO}$, carbohydrate; $\mathrm{CI}$, confidence interval. fined as UAE between 20 and $200 \mu \mathrm{g} / \mathrm{min}$ ) is associated with an increased incidence of cardiovascular morbidity and mortality [1-4]. Microalbuminuria may be present at the time of diagnosis of NIDDM [5-8] and is often associated with atherogenic risk factors, such as an abnormal lipoprotein metabolism, hyperglycaemia, obesity and hypertension [9-12]. Moreover, progression to overt clinical proteinuria (UAE $>200 \mu \mathrm{g} / \mathrm{min}$ ) is more likely to occur in microalbuminuric patients than in patients with normoalbuminuria (UAE $<20 \mu \mathrm{g} / \mathrm{min}$ ) [1].

Recent reports have demonstrated that an improvement of glycaemic control in newly-diagnosed 
NIDDM reduces and partly normalizes UAE $[5,6$, 13]. Furthermore, it has become increasingly clear that not only a restriction of the total caloric intake (in combination with a weight reduction), but also dietary composition affects metabolic parameters and may improve cardiovascular risk factors in some patients. The currently advised dietary composition of NIDDM patients suggests that saturated fat should be reduced through a high-carbohydrate (CHO), low-fat diet including $50 \%$ of energy from complex $\mathrm{CHO}, 30 \%$ energy from fat and about $20 \%$ from protein [14-16]. Moreover, unprocessed vegetables (i.e. fibre) should be implemented as a CHO source [17, 18].

Epidemiological studies from the Mediterranean area show a lower incidence of cardiovascular disease and a beneficial influence on the blood pressure in areas where people consume high amounts of monounsaturated fatty acids (MUFA) [19-21]. Moreover, intervention studies in both non-diabetic subjects and NIDDM patients have indicated that a high amount of CHO may cause untoward effects on metabolic risk factors [22-24]. Conversely, replacement of a high-CHO/low-fat diet by low-CHO/highfat diet including high amounts of unsaturated fat, and especially monounsaturated fat, may favourably influence glucose metabolism (including insulin sensitivity), lipoproteins and blood pressure [24-29]. In two recent studies a high-MUFA diet was found to be associated with a reduction in diurnal blood pressure in normotensive NIDDM subjects with normal $\mathrm{UAE}(<20 \mu \mathrm{g} / \mathrm{min})$ as compared to a CHO diet [29] or a diet rich in polyunsaturated fat [30]. The influence of dietary fat on albuminuria in diabetic patients has not received much attention $[31,32]$ and the effect of a monounsaturated fat diet has so far not been examined.

Whether a MUFA diet in NIDDM patients with microalbuminuria affects metabolic parameters, suppresses the blood pressure and alters UAE is unknown. Thus, in a cross-over design we compared the impact of 3 weeks' treatment with a MUFA-enriched diet with a standard $\mathrm{CHO}$ diet, on metabolic control, 24-h ambulatory blood pressure and UAE in a group of NIDDM patients with persistent microalbuminuria.

\section{Subjects and methods}

Ten NIDDM patients (seven men and three women) with persistent microalbuminuria were randomly selected from the outpatient clinics. Additional criteria for inclusion were: age 5075 years, diabetes duration greater than 1 year, and normal serum creatinine level. Patients with diabetic nephropathy, neuropathy or retinopathy (except background retinopathy) as well as patients taking hypolipidaemic agents were not included. Informed consent was obtained from each patient before taking part in the study, as well as ethical committee approval.
Study design. A total dietary registration of caloric intake for 4 days was performed in each patient and reviewed by a dietician. Based on food models and standard tables of food composition, individual isocaloric dietary schemes for a highCHO-/low-fat diet and a low-CHO/high-MUFA diet were computed [25], aiming at providing the patients with a weightmaintaining diet. Patients were then assigned to either a $\mathrm{CHO}$ diet or a diet rich in MUFA for 3 weeks. This was followed by a wash-out period of 3 weeks after which the patients were switched to the opposite diets for an additional 3 weeks. The energy composition of the prescribed CHO diet was: $50 \%$ $\mathrm{CHO}, 30 \%$ fat, of which $10 \%$ were MUFA. The MUFA-rich diet contained: $30 \%$ carbohydrate and $50 \%$ fat, of which $30 \%$ was MUFA. The amount of dietary fibre was $25 \mathrm{~g} / \mathrm{day}$ in both diets. As a source of MUFA cold-pressed virgin olive oil (Elanthy, Piraeus, Greece) was used. Four patients started on the $\mathrm{CHO}$ diet and six patients started on the MUFA diet. Special rolls and meat dishes containing $8 \mathrm{~g}$ and $30 \mathrm{~g}$ of olive oil, respectively, were provided frozen from the clinic together with olive oil. During the dietary intervention the patients visited the dietician once a week for reviewing of food schemes and weighing. Caloric intake adjustments were performed if body weight differed more than $500 \mathrm{~g}$ from the initial value. Registrations of caloric intake for 4 days were repeated at the end of both diet periods and used for computation of the actual energetic composition of the diets. Hypoglycaemic and antihypertensive drugs as well as insulin dosages were maintained constant throughout the study.

Before and after both diet periods, fasting blood samples were drawn in addition to measurements of 24 -h blood pressure and UAE. Plasma glucose was measured by a glucose oxidase technique, serum fructosamine by a spectrophotometric technique [33], and $\mathrm{HbA}_{1 \mathrm{c}}$ by HPLC [34]. Serum insulin was determined by radioimmunoassay as described by Ørskov et al. [35] with minor modifications (normal level of fasting insulin in 42 healthy subjects ( 23 men, 19 women; age: 37 (21-53) (mean (range)) years; body mass index (BMI): 24.2 (16.829.6) $\mathrm{kg} / \mathrm{m}^{2}$ ) was $6(4-7) \mathrm{mU} / \mathrm{l}$ ) (median $25^{\mathrm{th}}-75^{\text {th }}$ percentile)). Plasma C-peptide was assessed by a radioimmunoassay kit (Immunonuclear Corp., Stillwater, Minn., USA). Measurements of serum cholesterol by continuous-flow analysis [36], serum triglycerides by an enzymatic technique [37], serum (HDL)-cholesterol by a dextran sulphate- $\mathrm{Mg}^{2+}$ precipitation procedure [38] and serum creatinine by a modified Jaffe's reaction [39] were all adapted to the Technicon CHEM 1 (R) analyzer (Bayer A/s, Tarrytown, NY, USA). LDL-cholesterol and VLDL-cholesterol levels were calculated using the formula of Friedewald et al. [40]. Serum non-esterified free fatty acids were determined by a colorimetric method (Wako Chemicals, Neuss, Germany). UAE was measured by radioimmunoassay [41] and assessed as the mean of three 24-h collections. BMI was calculated as weight $(\mathrm{kg}) /$ height $(\mathrm{m})^{2}$ and used as an index of overall obesity.

Diurnal ambulatory blood pressure was measured by a portable automatic blood pressure monitor (Spacelabs model 90202, Redmond, Wash., USA) using oscillometry [42]. The device was programmed to measure blood pressure every $20 \mathrm{~min}$ between 06.00 and 24.00 hours and every hour during the night. Patients recorded actual time for going to bed and rising in the morning for accurate appraisal of day and night blood pressures.

\section{Statistical analysis}

Values are given as mean \pm SD or median $\left(25^{\text {th }}-75^{\text {th }}\right.$ percentiles). UAE was log-transformed due to the positively-skewed 
Table 1. Clinical characteristics of NIDDM patients studied

\begin{tabular}{lc}
\hline Sex (men/women) & $7 / 3$ \\
Age (years) & $66(40-71)$ \\
Diabetes duration (years) & $11 \pm 6$ \\
Fasting plasma glucose level $(\mathrm{mmol} / \mathrm{l})$ & $8.6 \pm 2.5$ \\
$\mathrm{HbA}_{1 \mathrm{c}}(\%)$ & $8.1 \pm 1.5$ \\
Body mass index $\left(\mathrm{kg} / \mathrm{m}^{2}\right)$ & $27.9 \pm 2.9$ \\
Serum creatinine $(\mu \mathrm{mol} / \mathrm{l})$ & $96 \pm 25$ \\
Diabetes treatment $(\mathrm{d} / \mathrm{o} / \mathrm{i})$ & $0 / 7 / 3$ \\
Antihypertensive treatment (yes/no) & $3 / 7$ \\
\hline
\end{tabular}

$\overline{\text { Mean } \pm S D \text {, median (range). d, Diet; o, oral hypoglycaemic }}$ agents; i, insulin

Table 2. Recorded energetic composition during 3 weeks of dietary intervention

\begin{tabular}{lcc}
\hline & CHO diet & MUFA diet \\
\hline Energy (kJ) & $6037 \pm 1785$ & $7203 \pm 1599^{\mathrm{a}}$ \\
Carbohydrate (\%) & $47.9 \pm 3.7$ & $34.2 \pm 4.0$ \\
Protein (\%) & $17.5 \pm 3.5$ & $13.4 \pm 2.7^{\mathrm{b}}$ \\
Fat (\%) & $29.9 \pm 3.8$ & $50.3 \pm 6.3$ \\
PUFA (\%) & $7.7 \pm 2.4$ & $6.7 \pm 1.1$ \\
MUFA (\%) & $9.0 \pm 1.4$ & $30.3 \pm 4.5$ \\
SAT (\%) & $10.2 \pm 1.8$ & $10.0 \pm 1.2$ \\
Alcohol (\%) & $1.5(0.0-8.0)$ & $1.0(0.0-4.0)$ \\
\hline
\end{tabular}

Mean \pm SD or median $\left(25^{\text {th }}-75^{\text {th }}\right.$ percentile $)$

${ }^{\mathrm{a}} p<0.001 ;{ }^{\mathrm{b}} p<0.03$ vs CHO diet

Table 3. Urinary excretion rates before and after 3 weeks of dietary intervention

\begin{tabular}{llllll}
\hline & \multicolumn{3}{l}{ CHO diet } & & \multicolumn{2}{l}{ MUFA diet } \\
\cline { 2 - 3 } \cline { 5 - 6 } \cline { 5 - 6 } & Before & After & & 162 & 149 \\
\hline $\begin{array}{l}\text { Sodium } \\
\text { (mmol/day) }\end{array}$ & 158 & 169 & & After \\
$\begin{array}{l}\text { Potassium } \\
\text { (mmol/day) }\end{array}$ & $72 \pm 23$ & $70 \pm 21$ & $70 \pm 24$ & $71 \pm 18$ \\
$\begin{array}{l}\text { Creatinine } \\
\text { (mmol/day) }\end{array}$ & $11.0 \pm 3.8$ & $10.8 \pm 3.8$ & & $10.4 \pm 2.9$ & $10.7 \pm 3.5$ \\
\hline
\end{tabular}

Mean \pm SD or median $\left(25^{\text {th }}-75^{\text {th }}\right.$ percentile $)$

Before vs After and CHO vs MUFA (ANOVA): NS

distribution and is presented as the geometric mean $\times 1 \div$ anti$\log$ SD. Where appropriate, $95 \%$ confidence intervals (CI) are indicated. Baseline and endpoint differences between treatments as well as within-treatment changes were analysed using Student's $t$-test for paired comparisons or Wilcoxon's test for matched pairs. Between-treatment comparisons of overall dietary effects were analysed by repeated-measures analysis of variance (ANOVA). Correlations were evaluated using Pearson's $r$ or Spearman's rho. A $p$-value less than 0.05 was considered statistically significant.

Power analysis. A mean change in 24-h systolic blood pressure of $9 \mathrm{~mm} \mathrm{Hg}$ (expected SD of the mean change: $9 \mathrm{~mm} \mathrm{Hg}$ ) or in 24-h diastolic blood pressure of $4 \mathrm{~mm} \mathrm{Hg}$ (expected SD of the mean change: $9 \mathrm{mmHg}$ ) holds a statistical power of $80.4 \%(\alpha=0.05)$ in a paired $t$-test. Similarly, expecting a mean reduction in albuminuria of $20 \%$ (UAE-final/UAEbaseline $=0.80$ ), calculation of power on the log-transformed figures (mean change -0.097 ) [expected $\mathrm{SD}$ of the mean change: $\log (1.200)]$ holds a power of $93 \%$.

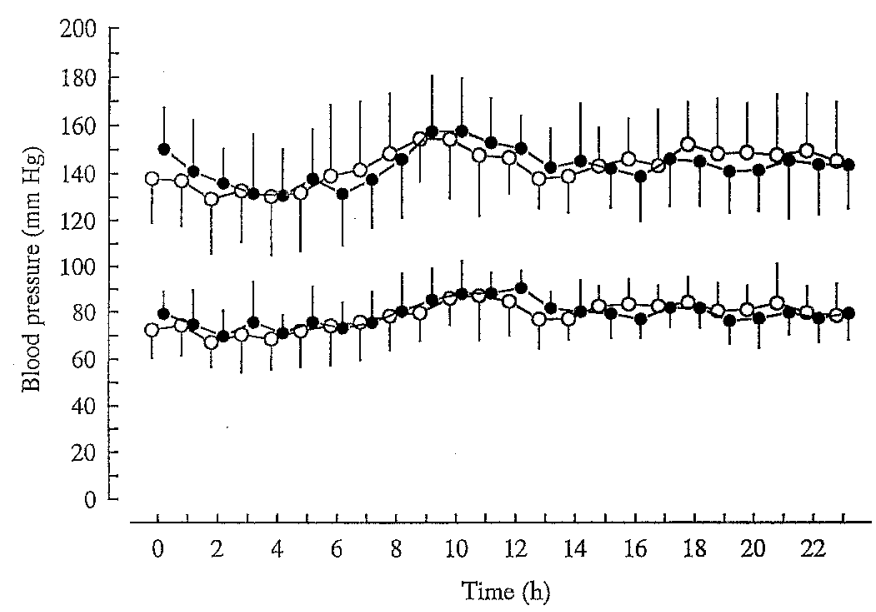

Fig.1. Diurnal systolic and diastolic blood pressures after 3 weeks treatment with a high carbohydrate/low fat diet $(0)$ and a low carbohydrate/high MUFA diet (•). No difference between the groups (ANOVA)

\section{Results}

Table 1 shows the clinical characteristics of the patients. Table 2 outlines the results of the energy composition of the diets as calculated from the individual registrations of food intake conducted at the end of each treatment period. The recorded protein content was slightly higher in the CHO diet than in the MUFA diet ( $62.1 \pm 9.3$ vs $56.4 \pm 12.4 \mathrm{~g} /$ day, $p<0.03$ ). Sodium and potassium intake, as estimated from the urinary electrolyte excretion rates were similar (Table 3). Both diets were well-tolerated and without significant adverse clinical effects. A slight decrease in body weight was noticed during both treatments (CHO: from $81.8 \pm 12.0$ to $81.0 \pm 12.2 \mathrm{~kg}, p<0.02$ vs MUFA: from $82.4 \pm 12.2$ to $81.6 \pm 11.8 \mathrm{~kg}, p<0.05$ ).

Figure 1 shows the $24-\mathrm{h}$ blood pressure profile as recorded at the end of each treatment period. Twenty-four-hour ambulatory blood pressure was similar before and after the CHO diet (from 145/78 $\pm 25 / 10$ to $143 / 79 \pm 19 / 10, \mathrm{NS}$; mean difference $(95 \% \mathrm{CI})-2$ $(-10-7) / 1(-2-4) \mathrm{mm} \mathrm{Hg})$ as well as after the MUFA diet (from 140/78 $\pm 16 / 8$ to $143 / 79 \pm$ $15 / 8 \mathrm{~mm} \mathrm{Hg}$ ), NS; mean difference (95\% CI) 4 $(-3-10) / 2(-1-5) \mathrm{mmHg}$. Moreover, blood pressure changes were comparable during the two diets both for the systolic (mean difference $(95 \% \mathrm{CI})-5$ $(-17-6) \mathrm{mm} \mathrm{Hg}$ and the diastolic blood pressure -1 $(-5-3)) \mathrm{mm} \mathrm{Hg}$. Furthermore, no changes were found in either day or night-time blood pressures (Table 4).

UAE remained stable both during the $\mathrm{CHO}$ diet (from $32.4 \times / \div 2.1$ to $36.0 \times / \div 1.9 \mu \mathrm{g} / \mathrm{min}$, NS; relative rise: $1.11(0.87-1.41)$ (mean ratio $(95 \% \mathrm{CI})$ ) as well as during MUFA (from $34.2 \times / \div 1.9$ to 32.1 $x / \div 2.1 \mu \mathrm{g} / \mathrm{min}, \mathrm{NS}$; relative rise: $0.94(0.78-1.12)$ (mean ratio $(95 \% \mathrm{CI})$ ). Moreover, no significant difference in the relative rise in UAE was found between the $\mathrm{CHO}$ and the MUFA diets (CHO ratio/ 
Table 4. Day- and night-time values during 24-h blood pressure and heart rate recordings

\begin{tabular}{lcclll}
\hline & \multicolumn{2}{l}{ CHO diet } & & \multicolumn{2}{l}{ MUFA diet } \\
\cline { 2 - 3 } \cline { 5 - 6 } & Before & After & & Before & After \\
\hline $\begin{array}{l}\text { Systolic } \\
\text { (diurnal) }\end{array}$ & $145 \pm 25$ & $143 \pm 19$ & & $140 \pm 16$ & $143 \pm 15$ \\
$\begin{array}{l}\text { Systolic } \\
\text { (daytime) }\end{array}$ & $148 \pm 25$ & $148 \pm 19$ & & $143 \pm 17$ & $146 \pm 16$ \\
$\begin{array}{l}\text { Systolic } \\
\text { (night-time) }\end{array}$ & $138 \pm 25$ & $133 \pm 21$ & & $131 \pm 17$ & $134 \pm 17$ \\
$\begin{array}{l}\text { Diastolic } \\
\text { (diurnal) }\end{array}$ & $78 \pm 10$ & $79 \pm 10$ & $78 \pm 8$ & $79 \pm 8$ \\
$\begin{array}{l}\text { Diastolic } \\
\text { (daytime) }\end{array}$ & $81 \pm 11$ & $82 \pm 10$ & $80 \pm 8$ & $81 \pm 8$ \\
$\begin{array}{l}\text { Diastolic } \\
\text { (night-time) }\end{array}$ & $72 \pm 11$ & $71 \pm 11$ & $71 \pm 10$ & $73 \pm 9$ \\
$\begin{array}{l}\text { Heart rate } \\
\text { (diurnal) }\end{array}$ & $76 \pm 9$ & $78 \pm 9$ & $79 \pm 11$ & $79 \pm 11$ \\
$\begin{array}{l}\text { Heart rate } \\
\text { (daytime) }\end{array}$ & $79 \pm 10$ & $83 \pm 12$ & $81 \pm 11$ & $81 \pm 13$ \\
$\begin{array}{l}\text { Heart rate } \\
\text { (night-time) }\end{array}$ & $68 \pm 6$ & $70 \pm 10$ & $70 \pm 6$ & $70 \pm 7$ \\
\hline
\end{tabular}

Mean \pm SD

All values NS

MUFA ratio: $1.18(0.87-1.60)$ (mean ratio (95\% CI)). As seen from Table 5 glycaemic control and plasma lipoprotein concentrations were unaltered during both diets. Compared to the $\mathrm{CHO}$ diet a significant reduction in LDL/HDL cholesterol ratio was found during the MUFA diet ( $p<0.03$ (ANOVA)). No significant correlations were found between changes in blood pressure, UAE or metabolic parameters.

\section{Discussion}

In a cross-over study in NIDDM patients with persistent microalbuminuria we found no differing effects on 24-h ambulatory blood pressure or UAE after 3 weeks' treatment with either a MUFA-rich or a standard CHO diet. Glycaemic control and lipoproteins were unaffected during treatment, although a reduction in the $\mathrm{LDL} / \mathrm{HDL}$ cholesterol ratio (thought to be an atherogenic risk marker) was noticed during the MUFA diet.

We used a 3 weeks' intervention design in order to compare the results with our previous study of normoalbuminuric NIDDM patients [29]. Other studies have demonstrated that a 3-week dietary intervention is sufficient to detect changes in metabolic control and lipoprotein concentrations [25]; and during recent years similar studies of NIDDM patients have also shown effects on metabolic control, lipids, blood pressure and insulin sensitivity [22, 23, 26, 27, 29, 43].

The difference in total energy consumption (Table 2) during the two dietary periods may have been

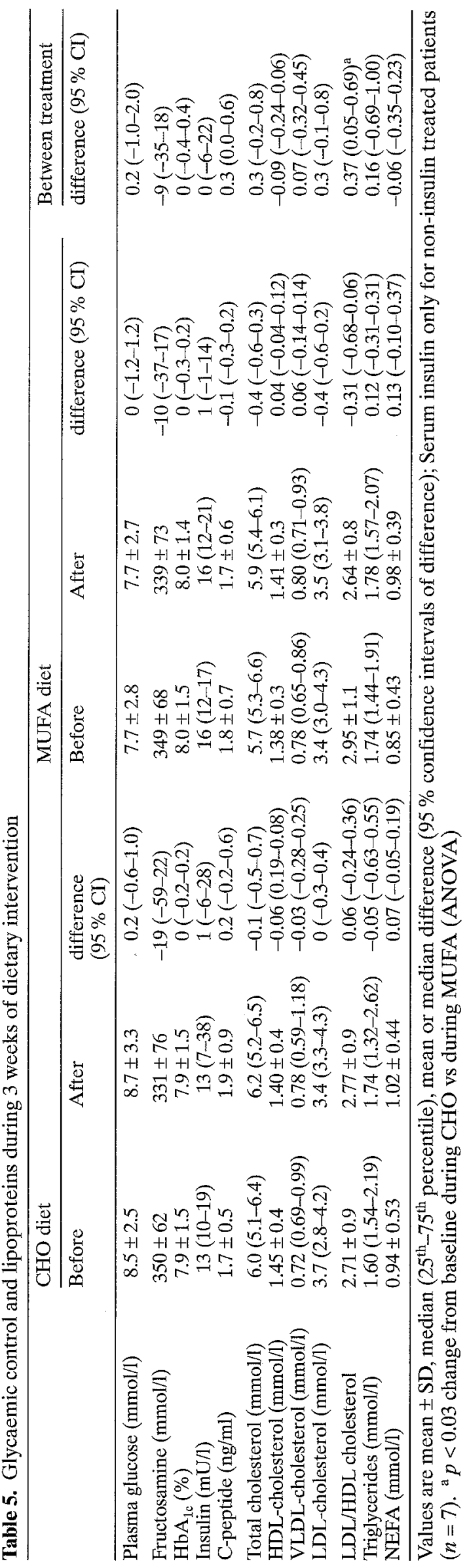


slightly overestimated, since the patients were monitored on a weekly basis and since the changes in body weight were small and similar $(<1 \mathrm{~kg})$ during both diets. A small weight reduction is common during this type of dietary intervention, as also seen in our patients, and is probably associated with the well-known tendency to underreporting (10-15\%) of energy content during food registration. The question arises whether this difference in energy and/or protein content could explain why no difference in blood pressure was detected as previously demonstrated in normoalbuminuric NIDDM patients [29]. To the authors' knowledge, no such evidence is presently available in the literature. From a theoretical point of view, a further increase in energy content in the $\mathrm{CHO}$ diet would also increase the amount of MUFA, making the difference in MUFA between the two diets smaller, and the amount of saturated fat would be increased. Theoretically, an increase in MUFA content would, if anything, favour a decrease in blood pressure, while increasing the amount of saturated fat would, if anything, favour an increase [44, 45]. No studies evaluating the effect of dietary protein restriction on blood pressure or albuminuria in NIDDM patients with normo- or microalbuminuria have been published. In insulin-dependent diabetic patients protein restriction is known to produce minor reductions in renal plasma flow, glomerular filtration rate, albuminuria and blood pressure [46]. However, the observed difference in the protein content in our study is very small compared to what is used in most clinical trials. Moreover, the protein content was already slightly higher during the $\mathrm{CHO}$ diet. Thus, increasing the energy content in the CHO diet would merely add to the difference in protein content.

It has long been recognized that a complementary exchange of dietary carbohydrate for unsaturated fat may influence blood pressure in both non-diabetic and diabetic subjects $[44,47,48]$. Recently, we found a significant reduction in day-time and 24 -h systolic and diastolic blood pressure in 15 normoalbuminuric NIDDM patients treated with a MUFA diet as compared with a standard CHO diet for 3 weeks [29]. Using the same design, however, we found no changes in blood pressure in microalbuminuric patients. The mechanism behind the blood pressure-lowering potency is so far unknown. Sacks et al. [49] observed no effects of MUFA on erythrocyte sodium-lithium countertransport activity, which is associated with essential hypertension. Studies in young Sprague-Dawley rats have documented that low-fat diets markedly reduce the receptor-mediated vessel reactivity, and particularly MUFA was observed to reduce the non-receptor-mediated contractile response [50]. Other studies in NIDDM patients have suggested an increased insulin sensitivity and a reduction in hyperinsulinaemia following the exchange of a $\mathrm{CHO}$ diet for a MUFA-rich diet $[26,27]$. In the latter study of mildly diabetic patients, however, only a slight tendency towards an improvement was observed. Hyperinsulinaemia may be a pathogenetic determinant in arterial hypertension [51-53], and it is possible that the blood pressure-lowering effect of MUFA may be mediated via an increased sensitivity to insulin action and a reduction in the concomitant hyperinsulinaemia. In fact, some reports have suggested that NIDDM patients with microalbuminuria, in general, may be more insulin-resistant, than are their normoalbuminuric counterparts [54-56]. As seen in Table 5 , no change was observed in insulin or C-peptide levels during either diet. This would, to some extent, offer an explanation for the lack of changes in both blood pressure, UAE and metabolic parameters in our patients, and the question arises whether a sufficient influence on the hyperinsulinaemia was achieved to actually elicit a suppressive action on the blood pressure and modify other parameters associated with the insulin-resistance syndrome $[57,58]$. In this context it is worth noticing that no other intervention modalities, except blood pressure reduction (especially systolic), have appeared to be effective in reducing microalbuminuria in NIDDM [59]. The long-term consequences are, however, not known, and different antihypertensive drugs may not cause similar effects on the level of albuminuria.

The LDL/HDL cholesterol ratio was significantly lowered during the MUFA diet as compared to the $\mathrm{CHO}$ diet. This is in accordance with other shortterm studies in NIDDM showing that MUFA-rich diets may lower the total cholesterol to HDL-cholesterol ratio [24, 27, 28]. Moreover, a decrease in HDL-cholesterol has been described during a highcarbohydrate diet, but this is usually omitted or even increased during the high-MUFA diet [22, 27, 28]. Some studies, but not all, also describe minor reductions in VLDL-cholesterol and serum triglyceride concentrations $[24,27,28,43]$. We found no changes in individual lipoprotein fractions. Furthermore, we observed no adverse effects on glycaemic control during the high-carbohydrate diet, probably because the composition of this diet was similar to the patients' usual diets. Plasma glucose and serum insulin concentrations are usually unaffected or slightly lowered during MUFA diets, whereas CHO diets may be associated with adverse effects on glycaemic control [25]. We did not measure day profile excursions in plasma glucose, serum insulin or triglycerides following a CHO or MUFA test meal, and it is important to realize that even though fasting levels of glucose metabolism and lipids are unchanged, significant differences may be obtained postprandially [24, $28,29,43]$. In our previous study of normoalbuminuric NIDDM patients we found higher day-long glucose levels but similar insulin and triglyceride levels during the high-CHO diet as compared to the high- 
MUFA diet [29]. In another study Garg et al. [60] found similar glucose and insulin day-long profiles but increased insulin sensitivity in NIDDM patients following a 3-week high-MUFA diet as compared to a high-CHO diet.

The different actions on blood pressure during a low-CHO/high-MUFA and a high-CHO/low-MUFA diet, as previously described in normoalbuminuric NIDDM patients [29] were not found in our microalbuminuric patients. In contrast to a number of studies glycaemic control and lipids were unaffected in the present study during both diets and no alterations in the microalbuminuria was observed. In conclusion, this and other studies suggest that MUFA represents an alternative in the diets of NIDDM subjects [60]. However, microalbuminuric patients may not be as sensitive to the effects of a change in dietary composition as are normoalbuminuric subjects. It is hypothesized that alterations in parameters associated with the insulin-resistance syndrome are not as easily modified in microalbuminuric patients, perhaps due to the prevalence of a further reduced insulin sensitivity, which is generally encountered in this group of patients. Whether a longer treatment with a MUFArich diet is necessary in NIDDM patients before any beneficial effects on cardiovascular risk markers can be unveiled remains to be elucidated.

Acknowledgements. We wish to thank Ms. M. Vesterlund, Ms. A.Saek, Ms. E. Sejer, Ms. E.Horneman, Ms. H.Petersen and Ms. M. Møller for excellent technical assistance. The study was supported by the Danish Research Council, the Nordic Insulin Foundation, Velux-fonden, Beckett-fonden, Jyllands Postens Fond, The Danish Diabetes Association, and The Institute of Experimental and Clinical Research, Aarhus University.

\section{References}

1. Mogensen CE (1984) Microalbuminuria predicts clinical proteinuria and early mortality in maturity-onset diabetes. N Engl J Med 310: 356-360

2. Jarrett RJ, Viberti GC, Argyropoulos A, Hill RD, Mahmud U, Murrells TJ (1984) Microalbuminuria predicts mortality in non-insulin-dependent diabetics. Diabet Med 1: 17-19

3. Mattock MB, Morrish NJ, Viberti G, Keen H, Fitzgerald AP, Jackson G (1992) Prospective study of microalbuminuria as predictor of mortality in NIDDM. Diabetes 41: 736-741

4. Schmitz A, Vaeth M (1988) Microalbuminuria: a major risk factor in non-insulin-dependent diabetes. A 10-year followup study of 503 patients. Diabet Med 5: 126-134

5. Schmitz A, Hansen HH, Christensen T (1989) Kidney function in newly diagnosed type 2 (non-insulin-dependent) diabetic patients, before and during treatment. Diabetologia 32: $434-439$

6. Patrick AW, Leslie PJ, Clarke BF, Frier BM (1990) The natural history and associations of microalbuminuria in type 2 diabetes during the first year after diagnosis. Diabet Med 7: 902-908

7. Olivarius, $\mathrm{N}$ deF, Andreasen AH, Keiding N, Mogensen CE (1993) Epidemiology of renal involvement in newly-diagnosed middle-aged and elderly diabetic patients. Cross- sectional data from the population-based study "Diabetes Care in General Practice", Denmark. Diabetologia 36: 1007-1016

8. Martin P, Hampton KK, Walton C, Tindall H, Davies JA (1990) Microproteinuria in type 2 diabetes mellitus from diagnosis. Diabet Med 7: 315-318

9. Niskanen L, Uusitupa M, Sarlund H et al. (1990) Microalbuminuria predicts the development of serum lipoprotein abnormalities favouring atherogenesis in newly diagnosed type 2 (non-insulin-dependent) diabetic patients. Diabetologia $33: 237-243$

10. Schmitz A, Christensen T, Møller A, Mogensen CE (1990) Kidney function and cardiovascular risk factors in non-insulin-dependent diabetics (NIDDM) with microalbuminuria. J Intern Med 228: 347-352

11. Schmitz A, Pedersen MM, Hansen KW (1991) Blood pressure by $24-\mathrm{h}$ ambulatory recordings in type 2 (non-insulin dependent) diabetics. Relationship to urinary albumin excretion. Diabete Metab 17: 301-307

12. Allawi J, Jarrett RJ (1990) Microalbuminuria and cardiovascular risk factors in type 2 diabetes mellitus. Diabet Med 7:115-118

13. Vora JP, Dolben J, Williams JD, Peters JR, Owens DR (1993) Impact of initial treatment on renal function in newly-diagnosed type 2 (non-insulin-dependent) diabetes mellitus. Diabetologia 36: 734-740

14. American Diabetes Association (1987) Nutritional recommendations and principles for individuals with diabetes mellitus: 1986. Diabetes Care 10: 126-132

15. Diabetes and Nutrition Study Group of the EASD (1988) Nutritional recommendations for individuals with diabetes mellitus. Diabetes Nutr Metab 1: 145-148

16. Pedersen O, Hermansen K, Palmvig B, Pedersen SE, Søndergaard K (1992) Recommendations for diabetic diet. Ugeskr Laeger 154: 940-941

17. Riccardi G, Rivellese AA (1991) Effects of dietary fiber and carbohydrate on glucose and lipoprotein metabolism in diabetic patients. Diabetes Care 14: 1115-1125

18. Anderson JW, Akanji AO (1991) Dietary fiber - an overview. Diabetes Care 14: 1126-1131

19. Keys A, Menotti A, Karvonen MJ (1986) The diet and 15year death rate in Seven Countries Study. Am J Epidemiol 124: 903-915

20. ERICA Research Group (1988) The CHD risk-map of Europe: the first report of the WHO-ERICA project. Eur Heart J 9 [Suppl 1]: 1-36

21. ERICA Research Group (1991) Prediction of coronary heart disease in Europe. The 2nd report of the WHO-ERICA Project. Eur Heart J 12: 291-297

22. Coulston AM, Hollenbeck CB, Swislocki AL, Chen YD, Reaven GM (1987) Deleterious metabolic effects of highcarbohydrate, sucrose-containing diets in patients with non-insulin-dependent diabetes mellitus. Am J Med 82: 213-20

23. Coulston AM, Hollenbeck CB, Swislocki AL, Reaven GM (1989) Persistance of hypertriglyceridemic effect of lowfat high-carbohydrate diets in NIDDM patients. Diabetes Care 12: 94-101

24. Garg A, Grundy SM, Koffler M (1992) Effect of high carbohydrate intake on hyperglycemia, islet function, and plasma lipoproteins in NIDDM. Diabetes Care 15: 15721580

25. Mensink RP, Katan MB (1992) Effect of dietary fatty acids on serum lipids and lipoproteins. A meta-analysis of 27 trials. Arterioscler Thromb 12: 911-919

26. Parillo M, Rivellese AA, Ciardullo AV et al. (1992) A highmonounsaturated-fat/low-carbohydrate diet improves pe- 
ripheral insulin sensitivity in non-insulin-dependent diabetic patients. Metabolism 41: 1373-1378

27. Garg A, Grundy SM, Unger RH (1992) Comparison of effects of high and low carbohydrate diets on plasma lipoproteins and insulin sensitivity in patients with mild NIDDM. Diabetes 41: 1278-1285

28. Garg A, Bonanome A, Grundy SM, Zhang ZJ, Unger RH (1988) Comparison of a high-carbohydrate diet with a high-monounsaturated-fat diet in patients with non-insulin-dependent diabetes mellitus. N Engl J Med 319: 829 834

29. Rasmussen OW, Thomsen C, Hansen KW, Vesterlund M, Winther E, Hermansen K (1993) Effects on blood pressure, glucose, and lipid levels of a high-monounsaturated fat diet compared with a high-carbohydrate diet in NIDDM subjects. Diabetes Care 16: 1565-1571

30. Thomsen C, Rasmussen O, Hansen K, Hermansen K (1993) Effects on blood pressure in non-insulin-dependent diabetic subjects (NIDDM): comparison of a diet rich in monounsaturated (MUFA) with a diet rich in polyunsaturated fatty acids (PUFA). Diabetes 2 [Suppl 1]: 49A (Abstract)

31. Hamazaki T, Takazakura E, Osawa K, Urakaze M, Yano S (1990) Reduction in microalbuminuria in diabetics by eicosapentaenoic acid ethyl ester. Lipids 25: 541-545

32. Dullaart RP, Beusekamp BJ, Meijer S, Hoogenberg K, van Doormaal JJ, Sluiter WJ (1992) Long-term effects of linoleic-acid-enriched diet on albuminuria and lipid levels in type 1 (insulin-dependent) diabetic patients with elevated urinary albumin excretion. Diabetologia 35 : 165-172

33. Boye N, Ingerslev J (1988) Rapid and inexpensive microdetermination of serum fructosamine results in diabetics, uraemics, diabetics with uraemia and healthy subjects. Scand J Clin Lab Invest 48: 779-783

34. Jeppsson JO, Jerntorp P, Sundkvist G, Englund H, Nylund $\mathrm{V}$ (1986) Measurement of hemoglobin $\mathrm{A}_{1 c}$ by a new 1 quid-chromatographic assay: methodology, clinical utility, and relation to glucose tolerance evaluated. Clin Chem 32: 1867-1872

35. Ørskov H, Thomsen AG, Yde H (1968) Wick-chromatography for rapid and reliable immunoassay of insulin, glucagon and growth hormone. Nature 219: 193-195

36. Lie RF, Schmitz JM, Pierre KJ, Gochman N (1976) Cholesterol oxidase-based determination, by continuous-flow analysis, of total and free cholesterol in serum. Clin Chem 22: $1627-1630$

37. Bucolo H, David H (1973) Quantitative determination of serum triglycerides by the use of enzymes. Clin Chem 19: 476-482

38. Warnick GR, Benderson J, Albers JJ (1982) Dextran sulfate- $\mathrm{Mg}^{2+}$ precipitation procedure for quantification of high-density-lipoprotein cholesterol. Clin Chem 28: 13791388

39. Fabiny DL, Ertinghausen G (1971) Automated reactionrate method for determination of serum creatinine with the Centrifichem. Clin Chem 17: 696-700

40. Friedewald WT, Levy RI, Frederikson DS (1972) Estimation of the concentration of low density lipoprotein cholesterol in plasma without use of the preparative ultracentrifuge. Clin Chem 18: 499-502

41. Christensen CH, Ørskov C (1984) Rapid screening PEG immunoassay for quantification of pathological microalbuminuria. Diabetic Nephrol 3: 92-94
42. O'Brien E, Mee F, Atkins N, O'Malley K (1991) Evaluation of the SpaceLabs 90202 non-invasive ambulatory recorder according to the AAMI Standard and BHS criteria. J Hum Hypertens 5: 223-226

43. Campbell LV, Marmot PE, Dyer JA, Borkman M, Storlien LH (1993) The high-monounsaturated fat diet as a practical alternative for NIDDM. Diabetes Care 17: 177-182

44. Smith-Barbaro PA, Pucak GJ (1994) Dietary fat and blood pressure. Ann Intern Med 98: 828-831

45. Strazzullo P, Ferro-Luzzi A, Siani A et al. (1986) Changing the Mediterranean diet: effects on blood pressure. J Hypertens 4: 407-412

46. Walker JD (1994) Non-glycaemic intervention in diabetic nephropathy: the role of dietary protein intake. In: Mogensen CE (ed) The kidney and hypertension in diabetes mellitus. 2nd edn. Kluwer Adademic Publishers, Boston Dordrecht London, pp 369-379

47. Iacono JM, Dougherty RM (1993) Effect of polyunsaturated fats on blood pressure. Annu Rev Nutr 13: 243-260

48. Malasanos TH, Stacpoole PW (1991) Biological effects of omega-3 fatty acids in diabetes mellitus. Diabetes Care 14: 1160-1179

49. Sacks FM, Stampfer MJ, Munoz A, McManus K, Canessa M, Kass EH (1987) Effect of linoleic and oleic acids on blood pressure, blood viscosity, and erythrocyte cation transport. J Am Coll Nutr 6: 179-185

50. Hodgkin DD, Boucek RJ, Purdy RE, Pearce WJ, Fraser IM, Gilbert RD (1991) Dietary lipids modify receptorand non-receptor-dependent components of alpha 1adrenoceptor-mediated contraction. Am J Physiol 261: R1465-R1469

51. Reaven GM (1991) Relationship between insulin resistance and hypertension. Diabetes Care 14: 33-38

52. Haffner SM, Ferrannini E, Hazuda HP, Stern MP (1992) Clustering of cardiovascular risk factors in confirmed prehypertensive individuals. Hypertension 20: 38-45

53. Modan M, Halkin H, Almog S et al. (1985) Hyperinsulinemia. A link between hypertension obesity and glucose intolerance. J Clin Invest 75: 809-817

54. Groop L, Ekstrand A, Forsblom C et al. (1993) Insulin resistance, hypertension and microalbuminuria in patients with type 2 (non-insulin-dependent) diabetes mellitus. Diabetologia 36: 642-647

55. Niskanen L, Laakso M (1993) Insulin resistance is related to albuminuria in patients with type II (non-insulin-dependent) diabetes mellitus. Metabolism 42: 1541-1545

56. Nosadini R, Solini A, Velussi M et al. (1994) Impaired insulin-induced glucose uptake by extrahepatic tissue is a hallmark of NIDDM patients who have or will develop hypertension and microalbuminuria. Diabetes 43: 491-499

57. Reaven GM (1988) Role of insulin resistance in human disease. Diabetes 37: 1595-1607

58. DeFronzo RA, Ferrannini E (1991) Insulin resistance. A multifaceted syndrome responsible for NIDDM, obesity, hypertension, dyslipidemia, and atherosclerotic cardiovascular disease. Diabetes Care 14: 173-194

59. Mogensen CE, Damsgaard EM, Frøland A, Nielsen S, de Fine Olivarius N, Schmitz A (1992) Microalbuminuria in non-insulin-dependent diabetes. Clin Nephrology 38 [Suppl 1]: 28-38

60. Garg A (1994) High-monounsaturated fat diet for diabetic patients. Is it time to change the current dietary recommendations? Diabetes Care 17: 242-246 